\title{
QUALITY OF LIFE IN PATIENTS WITH MENTAL AND BEHAVIORAL DISORDERS AFTER APPLICATION OF GROUP THERAPY
}

\author{
Maja Brkić, Ranko Kovačević, Dženita Hrvić, Zihnet Selimbašić, Esmina Avdibegović
}

(C) 2019 by Acta Medica Saliniana ISSN 0350-364X

DOI: 10.5457/511

Maja BRKIĆ,

Ranko KOVAČEVIĆ,

Dženita HRVIĆ,

Zihnet SELIMBAŠIĆ,

Esmina AVDIBEGOVIĆ

\begin{abstract}
Afiliations:
University Clinical Center Tuzla, Clinic for Psychiatry
\end{abstract}

Received:

25.07.2019.

Accepted:

01.11.2019.

Corresponding author:

Maja Brkić

Email: maja_b76@yahoo.com

Funding: none

Competing interests: none

\section{ABSTRACT}

Background: People with mental and behavioural disorders have low satisfaction of quality of life, due to numerous symptoms, as well as poor interpersonal relations, communications skills, low tolerance on frustration.

Aim: The aim of this paper was to evaluate whether there has been an improvement in satisfaction with the quality of life after the application of group therapy

Methods: The study included 100 patients who attended group therapy, for a period of 6-12 weeks. The instruments used at the beginning and at the end of the treatment were Outcome Questionnaire-45 which measured symptoms distress, interpersonal relations, and social roles, and MANSA questionnaire that measured satisfaction with the quality of life.

Results: In total sample $(\mathrm{N}=100)$ there was approximately equal number of women and men ( $51 \%$ vs. $49 \%)$. The average age of the subjects was $48.11 \pm 7.91$. Majority of respondents had depressive disorder (45\%). Measuring the mean values obtained on the OQ-45 questionnaire, it was found that after the application of group therapy a significant reduction of the level of dysfunction was achieved. A statistically significant difference was found in the areas of satisfaction with physical and mental health, and the overall score of the MANSA questionnaire.

Conclusion: Results show that patients reported lower symptoms distress and higher satisfaction with quality of life after attending group therapy, better interpersonal relations, lower risk of suicidal behaviour and substance abuse. Group therapy is successful intervention which helps patients improve quality of life.

Keywords: group therapy, mental disorders, behavioural disorders.

\section{INTRODUCTION}

Mental disorders and behavioural disorders are one of the leading public health problems and causes of disability in the world [1]. Persons with mental disorders and behavioural disorders have difficulties in interpersonal relationships and the social roles assigned, which affects their ability to successfully respond to the demands required by the community in which they function. Priebe et al. (2004) state that people who have sought psychiatric help, and have more post-traumatic, depressive and anxiety disorders, have poorer quality of life [2].

The research suggests that persistent mental disorders such as dysthymia, agoraphobia, generalized anxiety disorder, social phobia, schizophrenia, alcohol dependence and other psychoactive substances are associated with poor quality of life $[3,4,5]$.
One of the challenges in using the concept of "quality of life" as the basis for measuring the outcome of treatment is that it can be defined and, accordingly, measured in countless ways [6]. For this reason, the concept of quality of life is defined differently. One of the definitions of quality of life refers to the ability to perform social and personal tasks, appropriate to age, sex, intelligence and belonging to the existential class [7]. However, there are also views that the quality of life is the perception of an individual about his own situation in comparison with his goals based on the value system he has accepted. Therefore, quality of life involves overall satisfaction, or dissatisfaction with one's own life [8].

Bosnia and Herzegovina is a country that was affected by war, whose consequences are felt even today [9,10]. Among the important consequences of war include an increased number of health and mental health problems of the population 
in post-war communities [11]. Among other things, the consequences also affect the normal functioning of the population that was exposed to war, or numerous traumatic experiences. In addition, Bosnia and Herzegovina is a country in transition, with extremely unsatisfactory socio-economic conditions and a high unemployment rate, which is an additional pressure both, on the individual's mental health and on the quality of life. The results of the National Vietnamese study on re-adapting male and female veterans show that subjects with PTSD had a significantly increased risk of reduced functioning in different aspects of life $[12,13]$.

In order to make quality interventions plan to meet the needs of the patient, it is necessary to make the assessment of the quality of life in order to gain insight into the sphere of life in which the patient shows a reduced functionality. For this reason, a number of instruments are used, which in specific ways, measure the quality of life of persons with mental and behavioural disorders. Based on an adequate assessment, an intervention plan that is acceptable to the patient and effective is made.

In addition to pharmacotherapy interventions, in effort to help people with mental and behavioural disorders improve the quality of life, a range of psychotherapy interventions of different modalities are used. Wolberg (1995) states that psychotherapy is a method of treating the problem of an emotional nature with a psychological way, in which a therapist establishes professional relationships with a patient / client for the purpose of eliminating, modifying or alleviating the intensity of existing symptoms, and modifying disordered behaviour patterns as well as encouraging positive growth and development personality [14]. These kind of interventions help the patient gain insight, restore self-confidence, experience a corrective emotional experience, improve communication skills, raise the threshold of tolerance to frustration, improve interpersonal relationships, or functioning in general.

One of the possible approaches in dealing with patients with mental and behavioural disorders is the model of partial hospitalization, the type of day hospital, where group therapy is dominant intervention. Day hospital is a time-limited structured program of diagnostics, treatment and rehabilitation or recovery based on various psychotherapy and sociotherapy techniques. An important goal of this type of treatment is to improve interpersonal relations, communication with others, and adequate social functioning, which is achieved through various forms of psychotherapy activities, as well as group meetings in a friendly atmosphere [15].

\section{AIM}

The aim of the study was to examine whether and in which domains, improvement of quality of life satisfaction was achieved in patients with mental and behavioural disorders after group therapy was applied therapy.

\section{METHODS}

The study was a prospective two-year study conducted in the period from March 2017 to April 2019 at the Clinic for Psychiatry of Public Health Institution University Clinical Centre Tuzla. The study included 100 patients treated at the Day Hospital with established mental and behavioural disorder, where group therapy was applied as a treatment intervention. The research involved patients who during the research period consecutively came to the treatment at the Clinic for psychiatry, for whom the group therapy program was indicated and who gave voluntary consent for participation in the research before being introduced into group therapy. Respondents were involved in group treatment for 6-12 weeks, involving 24-48 sessions of a small therapeutic group and $24-48$ sessions of the middle therapeutic group. A small group was composed of 8 - 12 members, and middlegroupof 16-28members. Asmall therapeutic group was conducted by educators-rehabilitators with education from Gestalt-based psychotherapy and group analysis, a small sociotherapy group was conducted by nurse with introduction course from group-analyses, while the middle therapeutic group was conducted by psychiatrists with group analysis and group psychotherapy education. The research was conducted as a test-retest, immediately upon admission to the Day Hospital, and prior discharge from the Day Hospital. Respondents were tested using the Outcome Questionnaire -45 (OQ-45) rating their feelings on five-point Likert scale ranging from o to 4 . The score of three domains was calculated - Symptomatic Distress, Interpersonal Relations and Social Role as well as total score. It also highlights 4 items for risk behaviour [16]. To question satisfaction with the quality of life it was used Manchester Short Assessment of Quality of Life (MANSA), a seven-point scale which was designed to measure subjective satisfaction with the quality of various aspects of life (e.g. work, financial situation, family relationships, etc.), as well as the overall quality of life. An objective assessment of the quality of life refers to the existence of a friend, as to whether the patient has been the victim of physical violence, or the culprit of a crime [17].

The data were analyzed using SPSS 20.0 version for Windows, by calculating the mean, t-test, chi-square test and regression analysis. The value of $\mathrm{p}<0.05$ was taken for statistical significance.

\section{RESULTS}

In the total sample $(\mathrm{N}=100)$, the number of women and men was approximately equal ( $51 \%$ vs. $49 \%)$. The average age of the subjects was $48.11 \pm 7.91$. Sociodemographic characteristics of the respondents in respect to gender are shown in Table 1 . The average hospitalization length of patients in the Day Hospital was $74.47 \pm 19,712$ days. 
Table 1. Socio-demographic characteristics of respondents in respect to gender

\begin{tabular}{|c|c|c|c|c|}
\hline Characteristics & Male & Female & Total & $\chi^{2}, p$ \\
\hline & $\mathrm{N}(\%)$ & $\mathrm{N}(\%)$ & $\mathrm{N}(\%)$ & \\
\hline Education & & & & $\begin{array}{l}\chi^{2}=3.67 \\
\mathbf{p}=\mathbf{0 . 4 5 3}\end{array}$ \\
\hline Primary school & 3 & 7 & 10 & \\
\hline High school & 40 & 34 & 74 & \\
\hline College & 3 & 3 & 6 & \\
\hline Graduate & 2 & 5 & 7 & \\
\hline Postgraduate & 1 & 2 & 3 & \\
\hline Working status & & & & $\begin{aligned} \chi^{2} & =2.003 \\
\mathbf{p} & =\mathbf{0 . 3 6}\end{aligned}$ \\
\hline Employed & 29 & 30 & 59 & \\
\hline Unemployed & 20 & 19 & 39 & \\
\hline Retired & - & 2 & 2 & \\
\hline War status & & & & $\begin{array}{r}\chi^{2}=50.75 \\
\mathbf{p}<0.001\end{array}$ \\
\hline Demobilized person & 30 & 3 & 33 & \\
\hline Disabled war veteran & 6 & - & 6 & \\
\hline Civilian victim of war & 2 & 1 & 3 & \\
\hline None & 11 & 47 & 58 & \\
\hline Place of living & & & & $\begin{array}{l}\chi^{2}=5.78 \\
p=0.016\end{array}$ \\
\hline City & 23 & 36 & 59 & \\
\hline Village & 26 & 15 & 41 & \\
\hline Marital status & & & & $\begin{array}{l}\chi^{2}=\mathbf{9 . 1 3} \\
\mathbf{p}=\mathbf{0 . 0 6}\end{array}$ \\
\hline Single & 4 & 5 & 9 & \\
\hline Common law marriage & - & 4 & 4 & \\
\hline Married & 43 & 34 & 77 & \\
\hline Divorced & 2 & 6 & 8 & \\
\hline Widow/er & - & 2 & 2 & \\
\hline
\end{tabular}

In respect to mental disorders and gender, the highest number of respondents was with depressive disorder (45\%), of which $73 \%$ were women and $27 \%$ men (Table 2 ).

Table 2. Distribution of respondents in respect to diagnostic groups and gender

\begin{tabular}{|l|c|c|c|}
\hline Diagnostic groups & Male & Female & Total \\
\hline & $\mathrm{N}(\%)$ & $\mathrm{N}(\%)$ & $\mathrm{N}(\%)$ \\
\hline Depressive disorder & 12 & 33 & 45 \\
\hline Anxiety disorders & 4 & 3 & 13 \\
\hline Posttraumatic stress disorder & 9 & 4 & 24 \\
\hline Adjustment disorder & 17 & 7 & 6 \\
\hline $\begin{array}{l}\text { Permanent personality changes after } \\
\text { catastrophic experience }\end{array}$ & 5 & 1 & 5 \\
\hline Dissociative and other disorders & 2 & 3 & 100 \\
\hline Total & 49 & 51 & 0 \\
\hline
\end{tabular}

By measuring the mean values obtained on OQ-45, it was found that the average values, both of the total OQ45 score, as well as of the symptomatic distress, interpersonal relationships and social roles domains, upon the involvement in treatment were in the level of high dysfunction, and that after the application of group therapy, significant reduction in the level of dysfunction was achieved (Table 3 ).

Table 3. The mean values of treatment outcome measured OQ-45 upon admission and prior discharge from treatment $(\mathrm{N}=100)$ 


\begin{tabular}{|l|c|c|c|c|c|}
\hline \multirow{2}{*}{ Outcomes of treatment OQ-45 } & \multicolumn{2}{|c|}{$\begin{array}{c}\text { Upon admission to } \\
\text { treatment }\end{array}$} & \multicolumn{2}{c|}{$\begin{array}{c}\text { Prior discharge from } \\
\text { treatment }\end{array}$} & \multirow{2}{*}{$\mathrm{p}^{*}$} \\
\cline { 2 - 6 } & $\mathrm{M}$ & $\mathrm{SD}$ & $\mathrm{M}$ & $\mathrm{SD}$ & \\
\hline Total score OQ-45 & 104.78 & 23.31 & 96.62 & 27.16 & $<0.001$ \\
\hline Symptomatic distress & 61.85 & 13.75 & 55.51 & 15.27 & $<0.001$ \\
\hline Interpersonal relations & 21.09 & 7.44 & 20.23 & 7.78 & $<0.001$ \\
\hline Social role & 19.21 & 6.26 & 18.65 & 6.52 & 0.005 \\
\hline
\end{tabular}

After application of group therapy, significantly lower values were obtained at the level of suicidality (1.45 \pm 1.32 vs. $1.00 \pm 1.11)(\mathrm{t}$-test $=-3.857, \mathrm{p}<0.001)$, while there was no significant difference in values of abuse of alcohol and psychoactive substances $(0.27 \pm 0.52 \mathrm{vs}$. $0.38 \pm 0.75)(\mathrm{t}$-test $=-1,137, \mathrm{p}=0.257)$ and aggressiveness $(1.73 \pm 1.48$ vs. $1.78 \pm 1.45)(\mathrm{t}-$ test $=-0.339, \mathrm{p}=0.735)$. Majority of respondents after treatment did not have suicidal thoughts and did not abuse substances, while a slightly higher number of them manifested violence (Table 4.)

Table 4: Distribution of patients in respect to risky behaviours upon admission and prior to discharge from treatment $(\mathrm{N}=100)$

\begin{tabular}{|l|l|l|l|l|l|l|l|l|}
\hline \multirow{2}{*}{$\begin{array}{l}\text { Risky } \\
\text { behaviour } \\
\text { measured by }\end{array}$} & \multicolumn{3}{|c|}{$\begin{array}{l}\text { Upon admission to } \\
\text { treatment }\end{array}$} & \multicolumn{4}{|c|}{$\begin{array}{l}\text { Prior } \\
\text { discharge from } \\
\text { treatment }\end{array}$} \\
\cline { 2 - 9 } & \multicolumn{2}{|c|}{ Yes } & \multicolumn{2}{|c|}{ No } & \multicolumn{2}{c|}{ Yes } & No & \\
\cline { 2 - 9 } & $\mathrm{N}$ & $\%$ & $\mathrm{~N}$ & & $\mathrm{~N}$ & $\%$ & $\mathrm{~N}$ & $\%$ \\
\hline Suicidality & 68 & & 32 & & 56 & & 44 & \\
\hline $\begin{array}{l}\text { Substance } \\
\text { abuse }\end{array}$ & 29 & & 71 & & 26 & & 74 & \\
\hline & 68 & & 32 & & 73 & & 27 & \\
\hline
\end{tabular}

Although in all domains on the questionnaire satisfaction with quality of life was found to be higher mean values at the end of the treatment compared to the mean at the beginning of the treatment, a statistically significant difference was found in the domains of satisfaction with physical health, mental health and the overall score of the MANSA questionnaire (Table 5).

When asked if they have someone they can call a close friend 78/100 patients responded positively upon admission to treatment, while the $71 / 100$ patients responded positively at end of the treatment. When asked if they had seen one of their friends in the past week, 55/100 patients responded positively upon admission to the treatment, while at the end of treatment, 63/100 patients responded positively, and there was significant difference $\left(\chi_{2}=18.568, p<0.001\right)$, comparing beginning and end of the treatment. When asked if they were accused of a criminal offense in the past year, 3/100 patients responded positively, and 13/10o patients responded positively to the question of whether they were victims of physical violence in the past year.

Upon to admission to treatment, a higher number of patients with depression had suicidal ideations compared to the number of patients with other mental disorders, but without statistically significant difference ( $\left.\chi^{2}=0.364, p=0.546\right)$. After completing treatment suicidality was reduced in a significant number of patients without depression, but without statistically significant difference $\left(\chi^{2}=0.3778, p=\right.$ 0.052). No significant difference was found in the number of patients with depression and other mental disorders regarding alcohol and other substance abuse prior admission $(\chi 2=3.219, \mathrm{p}=0.073)$ and prior discharge from treatment $\left(\chi^{2}=1.531, p=0.216\right)$. Higher number of patients with other mental disorders than patients with depression showed symptoms of aggressiveness prior discharge from treatment, but without statistically significant difference $\left(\chi^{2}=1.665\right.$, $\mathrm{p}=$ 0.197) (Table 5).

Table 5. Distribution of patients with depression and other mental disorders related to risk behaviour $(\mathrm{N}=$ 100)

\begin{tabular}{|l|l|c|c|c|c|}
\hline & & \multicolumn{2}{|c|}{$\begin{array}{c}\text { Upon admission to } \\
\text { treatment }\end{array}$} & $\begin{array}{c}\text { Prior discharge } \\
\text { from treatment }\end{array}$ & \\
\hline & & $\begin{array}{c}\text { Depressive } \\
\text { disorder } \\
(\mathrm{n}=45) \\
\mathrm{N}(\%)\end{array}$ & $\begin{array}{c}\text { Other } \\
\text { mental } \\
\text { disorders } \\
(\mathrm{n}=55) \\
\mathrm{N}(\%)\end{array}$ & $\begin{array}{c}\text { Depressive } \\
\text { disorder } \\
(\mathrm{n}=45) \\
\mathrm{N}(\%)\end{array}$ & $\begin{array}{c}\text { Other } \\
\text { mental } \\
\text { disorders } \\
(\mathrm{n}=55) \\
\mathrm{N}(\%)\end{array}$ \\
\hline $\begin{array}{l}\text { Suicid- } \\
\text { ality }\end{array}$ & Yes & $32(71.1)$ & $36(65.5)$ & $30(66.7)$ & $26(47.3)$ \\
\cline { 2 - 7 } $\begin{array}{l}\text { Sub- } \\
\text { stance } \\
\text { abuse }\end{array}$ & $13(28.9)$ & $19(34.5)$ & $15(33.3)$ & $29(52.7)$ \\
\cline { 2 - 7 } & Yes & $9(20.0)$ & $20(36.4)$ & $9(20.0)$ & $17(30.9)$ \\
\hline $\begin{array}{l}\text { Aggres- } \\
\text { siveness }\end{array}$ & Yes & $31(68.9)$ & $35(63.6)$ & $36(80.0)$ & $38(69.1)$ \\
\cline { 2 - 7 } & No & $14(31.1)$ & $18(32.7)$ & $30(66.7)$ & $43(78.2)$ \\
\hline
\end{tabular}

Table 6. Mean values of domain of satisfaction with the quality of life upon admission and prior discharge from treatment 


\begin{tabular}{|l|c|c|c|c|c|c|}
\hline \multirow{2}{*}{ Domains of satisfaction with quality of life } & \multicolumn{2}{|c|}{$\begin{array}{c}\text { Upon admission to } \\
\text { treatment }\end{array}$} & \multicolumn{2}{|c|}{$\begin{array}{c}\text { Prior discharge } \\
\text { from treatment }\end{array}$} & \multirow{2}{*}{$\mathrm{t}$} & \multirow{2}{*}{$\mathrm{p}$} \\
\cline { 2 - 5 } & $\mathrm{M}$ & $\mathrm{SD}$ & $\mathrm{M}$ & $\mathrm{SD}$ & & \\
\hline Satisfaction with personal life & 3.80 & 1.43 & 3.95 & 1.38 & -1.20 & 0.223 \\
\hline $\begin{array}{l}\text { Satisfaction with employment/unemployed/ } \\
\text { being retired }\end{array}$ & 2.87 & 1.62 & 2.88 & 1.61 & -0.65 & 0.948 \\
\hline Satisfaction with financial situation & 3.40 & 1.69 & 3.46 & 1.70 & -0.586 & 0.559 \\
\hline $\begin{array}{l}\text { Satisfaction with number and quality of } \\
\text { friendships }\end{array}$ & 3.78 & 1.38 & 3.92 & 1.35 & -1.050 & 0.296 \\
\hline Satisfaction with free time activities & 3.34 & 1.39 & 3.57 & 1.39 & -1.950 & 0.054 \\
\hline Satisfaction with accommodation & 5.05 & 1.38 & 5.01 & 1.42 & 0.373 & 0.710 \\
\hline Satisfaction with personal security & 3.81 & 1.43 & 3.95 & 1.49 & -1.000 & 0.320 \\
\hline $\begin{array}{l}\text { Satisfaction with household inmates/or if } \\
\text { living alone }\end{array}$ & 5.11 & 1.54 & 5.15 & 1.46 & -0.327 & 0.744 \\
\hline Satisfaction with sexual life & 3.74 & 1.86 & 3.87 & 1.76 & -0.912 & 0.364 \\
\hline Satisfaction with family & 4.90 & 1.50 & 4.91 & 1.43 & -0.080 & 0.936 \\
\hline Satisfaction with physical health & 3.14 & 1.33 & 3.53 & 1.34 & -3.236 & 0.002 \\
\hline Satisfaction with mental health & 2.52 & 1.14 & 3.20 & 1.46 & -5.529 & $<0.001$ \\
\hline MANSA Total & 3.79 & 0.90 & 3.95 & 1.04 & -2.594 & 0.011 \\
\hline
\end{tabular}

${ }^{*}$ t-test

Using regression analysis, it was found that $77.6 \%$ of the total variance of satisfaction with quality of life can be explained by indicators of outcomes group treatment $[\mathrm{F}(3.100)=95.804, \mathrm{p}<0.001]$, with a significant interpersonal relationship $(\beta=-0.636, p<0.001)$ and symptoms of distress $(\beta=-0.291, p=0.002)$.

\section{DISCUSSION}

An analysis of the results of this study suggests a significant improvement in overall satisfaction with the quality of life, physical and mental health of patients with mental and behavioural disorders after application of group therapy. The results obtained showed that group therapy as a psychological intervention applied within structured Day hospital treatment contributed to improving the satisfaction with quality of life by improvement of interpersonal relationships and reduction of distress. A similar study conducted in Croatia on 124 patients showed that after a quarterly treatment in the Day hospital, patients assessed their self-esteem, overall satisfaction with the quality of life, as well as different domains of quality of life (satisfaction with physical and mental health, and satisfaction with the environment) as significantly improved [15]. Effectiveness of psychological interventions on improving of satisfaction with quality of life was found in patients with somatic diseases in the co-morbidity with mental disorders, schizophrenia, and other general mental disorders $[18,19,20]$.

In this study, it was found that patients after 6-12 weeks of treatment estimated that there was a decrease in the level of total distress and improvement in interpersonal relationships. On the domain that shows functioning in social roles, there were no significant changes. One of possible reasons for the occurrence of these changes may be found in the fact that the application of group therapy in structured and safe setting encourages acceptance, establishment of relations with others, communication and understanding with constant support, and provides opportunities for correction and rehabilitation. The absence of changes in the domain of a social role can simply be explained by the fact that patients were undergoing treatment within same family, educational, professional status as they were admitted to treatment, and changes in this domain were not expected. This study found that there was a decrease in the value of the risk behaviour indicator, especially suicide and abuse of psychoactive substances. However, with aggressiveness there was a slight increase in mean values. Although this is a slight increase, it can partly be explained by the fact that the 6-12-week period is too short for significant correction, of the behaviour acquired during life, to occur and to be fixed. For such a short period we could say that the patient is still in the stage of acquiring insight and entering the processing. A survey conducted by Mayes et al. (2001), working with a group of children and adolescents, precisely says that the length of treatment is related to a positive response to treatment [21].

It has also been found reduction in suicidality and substance abuse in a higher number of patients with other mental disorders than in patients with depression. In total sample there were 46 patients with disorders related to stress and trauma (PTSD, adjustment disorder, permanent personality disorder). Suicidality and substance abuse are common signs of these disorders, because of difficulties in coping with trauma symptoms and achieving of normalization of experiences, which may be reduced applying group therapy in Day hospital treatment [22,23].

Madan and Schwartz (2016) showed with the results of a study conducted in Canada on a group of geriatric patients, on the outcomes of group therapy in the Day hospital setting, that learning process from other members was a crucial for the treatment. 
Group therapy was a place to share and participate in the growth of others, as well as the support of other members of the group who provided useful feedback [24]. A survey conducted by Hubble et al (1999) shows that the relationship factors are responsible for $30 \%$ of the changes that patients achieve [25]. In this study, we found that interpersonal relationships had a significant role in improving satisfaction with the quality of life of patients treated with group therapy in a Day hospital.

There are several limitations to this research. The main limitations relate to the sample, the measuring instruments used, and the research design. Data were collected from patients treated at Day hospital who were in heterogeneous treatment groups with respect to diagnoses of mental disorder, traumatic experiences, gender, age, and other sociodemographic variables. Thus, the generalization of the results obtained to a larger group of patients with respect to individual mental and behavioural disorders is limited. The strength of the research is also diminished by the sample size. Furthermore, multiple modalities of group therapy were applied during Day hospital treatment, which is a limiting factor in assessing the effectiveness of individual modalities of group therapy and applying theoretical explanations of its effects on symptom reduction and consequently satisfaction with quality of life. Another significant limitation concerns measurement instruments and research design. Selfassessment scales were used in this study as the primary source of data collection, and are therefore based on perceived abilities rather than objective indicators. This is particularly related to the symptoms of distress and risky behaviour, which require a structured clinical interview. The main limitation in the research design is that this study did not include a control group and that the assessment of the effect of group therapy on quality of life satisfaction was not followed over more than two time points. The quality of the study would be improved by monitoring the effect of group therapy 6 to 12 months after completion of treatment, which would help to better evaluate the long-term effect. Although the research has several limitations, the results obtained indicate that group therapy is effective and that further methodologically sophisticated research is necessary.

\section{CONCLUSION}

Group therapy treatment conducted by educated group therapists within program of Day hospital treatment can be effective for patients with various mental and behavioural disorders and contribute to improving the quality of life satisfaction. The results of this study suggest that improvement in interpersonal relations and reduction of distress achieved by application of group therapy had a significant share in increasing the value of overall satisfaction with the quality of life. Taking into account the above mentioned, it can be concluded that group therapy as a psychological intervention gave positive outcomes, as well as guidelines for further improvement and application of group therapy as a method of choice, in the treatment of patients with mental and behavioural disorders.

\section{REFERENCES}

1. World Health Organization (?2003)? Investing in mental health. World Health Organiza-tion. http://www.who.int/iris/ handle/10665/42823

2. Priebe S, Janković Gavrilović J, Schutzwohl M, Galeazzi GM, Lečić-Toševski D, Ajduković D, Frančišković T, Kučukalić A, Popovski M (2004) Study oflong term clinical and social outcomes after war experiences in ex Yugoslavia - methodsof the „Connect project“. Psychology Today. 36 (1): 111-122.

3. Saarni S, Viertiö S, Perälä J, Koskinen S, Lönnqvist J, Suvisaari J (2010) Quality of life of people with schizophrenia, bipolar disorder and other psychotic disorders. Br J Psy-chiatry. 197(5): 386-394. doi:10.1192/bjp. bp.109.076489

4. Gigantesco A, Giuliani M (2011) Quality of life in mental health services with a focus on psychiatric rehabilitation practice. Ann Ist Super Sanità. 47(4):363-372.

5. Saarni S, Suvisaari J, Sintonen H et al. (2007) Impact of psychiatric disorders on healthrelated quality of life: General population survey. $\mathrm{Br} J$ Psychiatry. 190(4): 326-332. doi:10.1192/bjp.bp.106.025106

6. Connell J, Brazier J, O'Cathain A, Lloyd-Jones M, Paisley S (2012) Quality of life of people with mental health problems: a synthesis of qualitative research. Health and Qual-ity of Life Outcomes.10(1):138.

7. Spencer N (2006) Socioeconomic determinants of health related quality of life in child-hood and adolescence: Results from a European study. Child Care Health Develop-ment.32:603-6o4.

8. Ravens-Sieberer U, Gosc A, Abel T, Auqier T, Bellach BM, Bruil J, Dur W, Power M, Rajmil L (2001) Quality of life in children and adolescents: A Europeanpublic health per-spective. Social and Preventive Medicine.46:294-302.

9. Mollica RF, McInnes K, Sarajlic N, Lavelle J, Sarajlic I, Massagli MP (1999) Disability associated with psychiatric comorbidity and health status in Bosnian refugees living in Croatia. Journal of the American Medical Association. 282(5):433-439.

10. UNHCR (2006) The state of the worlds refugees 2006. Retrieved July 18, 2019, from https://www.unhcr.org/publications/ sowr/4a4dc1a89/state-worlds-refugees2 o o 6-human-dis placement-newmillennium.html

11. Pizarro J, Silver C, Prause J A (2006) Physical and mental health costs of traumatic war experiences among civil war veterans. Archives of General Psychiatry.63:193- 200.

12. Zatzick DF, Marrnar CR, Weiss DS, Browner 
WS, Metzler TJ, Golding JM, Stewart A, Schlenge WE, Wells KB (1997) Posttraumatic stress disorder and functioning and quality of life outcomes in a nationally representative sample of male Vietnam veterans. Am J Psychiatry.154:1690-1695.

13. Zatzick DF, Weiss DS, Marmar CR, Metzler TJ, Wells K, Golding JM, Stewart A, Schlenger WE, Browner WS (1997) Post-traumatic stress disorder and functioning and quality of life outcomes in female Vietnam veterans. Mil Merl. 162(10):661-665.

14. Wolberg LR (1995) The tehnique of psychotherapy, (4th edition). Jason Aronson, Inc: New York.

15. Šago D, Lovretić V, Habuš K, Ivezić E, Bogović Dijaković A, Đogaš VV, Filipčić I (2019) Improving the quality of life during treatment in the Day hospital for early intervention in Psychiatric Hospital "Sveti Ivan". Psychiatr Danub. 31(2):190-195.

16. Lambert M J, Hansen NB, Umphress V, Lumen K, Okiishi J, Burlingame GM, Reisenger, C. W. (1996). Administration and Scoring Manual for the OQ-45.2. Stevenson MD: American Professional Credentialing Services LLC.

17. Priebe S, Roder-Warner U, Kaiser W (1999) Application and results of the Manchester Short Assessment of Quality of Life (MANSA). International Journal of Social Psychia-try.45:7-12.

18. Ruesch M, Helmes AW, Bengel J. (2015) Immediate help through group therapy for patients with somatic diseases and depressive or adjustment disorders in outpatient care: study protocol for a randomized controlled trial. Trials.16:287.doi 10.1186/s13063-015o801-3

19. Kunikata H, Yoshinaga N, Shiraishi Y, Okada Y (2016)Nurse-led cognitive-behavioral group therapy for recovery of self-esteem in patients with mental disorders: A pilot study. Jpn J Nurs Sci.13:355-364

20. Soliman ES, Mahdy RS, Fouad HA (2018) Impact of psychoeducation program on quali-ty of life of schizophrenic patients and their caregivers. Egypt J Psychiatr.39:35-41

21. Mayes S, Krecko VF, Calhoun SL, et al. (2001) Variables related to outcome following child psychiatric hospitalization. General Hospital Psychiatry.23:278-284.

22. Ruzek JI, Young BH, Walser RD (2003) Group treatment of Posttraumatic Stress Disor-der and other trauma-related problems. Primary Psychiatry. 10:53-57.

23. Sloan DM, Bovin MJ, Schnurr PP (2012) Review of group treatment for PTSD. Jour-nalof Rehabilitation Research\& Development.49:689-702. doi:10.1682/ JRRD.2011.07.0123)

24. Madan RI,Schwartz K (2017) A Qualitative Study of Psychiatric Day Hospital for Geriat-ric Depression. J Psychiatry Mental Disord.2(1):1005.
25. Hubble MA, Duncan BL, Miller SD (1999) The heart and soul of change: What works in therapy? Washington, DC: American Psychological Association.
Scan this QR code with your mobile device for instant access to the current Issue of Acta Medica Saliniana

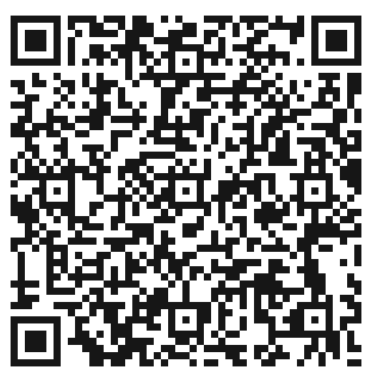

